\title{
Smoking and optic neuritis
}

\author{
G. D. PERKIN \\ P. BOWDEN \\ M.B., M.R.C.P. \\ M.B., M.R.C.P. \\ F. Clifford Rose* \\ F.R.C.P.
}

Medical Ophthalmology Unit, Lambeth Hospital, London SE11 4TH

\begin{abstract}
Summary
The effect of smoking on the recovery of visual function after an attack of optic neuritis has been assessed in 125 patients. Heavy smokers were found to have a higher incidence of red/green colour vision defects than non-smokers. The possible implications of this finding are discussed.

One patient is described in whom smoking caused transient blurring of vision. The effects of nicotine on the central nervous system are reviewed, and a pathophysiological mechanism suggested for this phenomenon.
\end{abstract}

\section{Introduction}

Smoking can produce a worsening of neurological symptoms in multiple sclerosis (Courville, Maschmeyer and Delay, 1964) spino-cerebellar degeneration (Spillane, 1955) and the Shy-Drager syndrome (Johnson et al., 1966; Graham and Oppenheimer, 1969). Well recognized factors producing transient worsening of vision in patients who have had optic neuritis-Uhthoff's syndrome-include exercise, eating and hot baths but smoking as such a factor has been only rarely reported (Courville et al., 1964). We are presenting the findings of the effect of smoking in a series of patients with optic neuritis.

\section{Methods}

One-hundred-and-twenty-five patients admitted with a diagnosis of optic neuritis to the Medical Ophthalmology Unit of the Royal Eye Hospital have been followed up as out-patients.

Optic neuritis was defined as a syndrome characterized by unilateral blurred vision, usually a central scotoma, occurring more commonly in women between the ages of 18 and 55 years, associated with pain on eye movement and resolving within a few months to leave temporal pallor of the optic disc (Rose, 1972). All patients had visual acuities recorded on admission. and during subsequent recovery.

* Address for reprints: Department of Neurology, Charing Cross Hospital, London W6 8RF.
At a follow-up designed to assess the prevalence of multiple sclerosis in these patients (Rose et al., 1972), the incidence of transient visual blurring was elicited, together with possible precipitating factors; visual acuities and colour vision were recorded, and macular thresholds and visual fields were measured using the Friedmann Visual Field analyser.

Any patient with previous, or subsequent, attacks of optic neuritis in the same eye has been excluded. Patients were followed up for a minimum period of 6 months after admission and those with continuing improvement in visual acuity at the last attendance were excluded. Those whose visual acuity did not return to normal (6/6) were accepted if the visual acuity on at least two successive readings was stable. A field index was performed on one occasion during follow-up; field indices obtained within 6 months of admission were discarded. Macular thresholds have been used only if two successive stable values had been recorded or, with isolated estimations, at least 6 months had elapsed from the original attack.

\section{Results}

Table 1 shows details of visual function in patients at the time of their original admission. Patients whose smoking history was unknown, those with a history of symptoms exceeding 1 month and pipesmokers were excluded. Macular thresholds and field indices were recorded at the onset in insufficient numbers to make comparison worthwhile.

Table 2 shows various parameters of visual function at follow up.

Of 125 patients, a history of transient blurring in the period following an attack of optic neuritis was obtained in forty-one $(32.8 \%)$. Precipitating factors are shown in Table 3 and although many of these patients were affected by more than one factor, only one patient had noted an effect from smoking; this patient was similarly affected by exercise, temperature change and affective disturbance.

Although the proportion of heavy smokers with a 
TABLE 1. Visual acuity on admission

\begin{tabular}{lccc}
\hline & $\begin{array}{c}\text { Non-smokers } \\
\text { (A) }\end{array}$ & $\begin{array}{c}\text { Less than twenty } \\
\text { cigarettes/day } \\
\text { (mean ten) } \\
\text { (B) }\end{array}$ & $\begin{array}{c}\text { Twenty or more } \\
\text { cigarettes/day } \\
\text { (mean twenty-five) } \\
\text { (C) }\end{array}$ \\
\hline $\begin{array}{l}\text { No. } \\
\text { Mean age (years) }\end{array}$ & 45 & 44 & 36 \\
$\begin{array}{l}\text { Proportion of females } \\
\text { Length of history before }\end{array}$ & 34 & $32 \cdot 7$ & 33 \\
admission (days) & $86.6 \%$ & $56 \cdot 8 \%$ & $55 \%$ \\
$\begin{array}{l}\text { Proportion with visual acuity of } \\
\text { 6/36 or better at onset }\end{array}$ & 14.9 & 16 & $16 \cdot 7$ \\
\hline
\end{tabular}

TABLE 2. Visual function on follow-up

\begin{tabular}{|c|c|c|c|}
\hline & $\begin{array}{l}\text { Non-smokers } \\
\text { (A) }\end{array}$ & $\begin{array}{l}\text { Less than twenty } \\
\text { cigarettes a day } \\
\text { (B) }\end{array}$ & $\begin{array}{l}\text { Twenty or more } \\
\text { cigarettes a day } \\
\text { (C) }\end{array}$ \\
\hline Proportion reaching VA of $6 / 6$ & $\begin{array}{l}90.4 \% \\
\text { s.e. } 4.01\end{array}$ & $\begin{array}{l}76.6 \% \\
\text { s.e. } 6 \cdot 18\end{array}$ & $\begin{array}{l}83 \cdot 4 \% \\
\text { s.e. } 5 \cdot 67\end{array}$ \\
\hline Mean field index at follow-up & $\begin{array}{l}1.97 \\
\text { s.d. } 1 \cdot 65\end{array}$ & $\begin{array}{l}1 \cdot 71 \\
\text { s.d. } 1 \cdot 60\end{array}$ & $\begin{array}{l}1 \cdot 54 \\
\text { s.d. } 1 \cdot 24\end{array}$ \\
\hline $\begin{array}{l}\text { Mean time from onset to field } \\
\text { index (months) }\end{array}$ & $22 \cdot 8$ & $26 \cdot 0$ & $31 \cdot 7$ \\
\hline Final macular threshold & $\begin{array}{l}2 \cdot 41 \\
\text { s.d. } 0 \cdot 41\end{array}$ & $\begin{array}{l}2 \cdot 18 \\
\text { s.d. } 0 \cdot 39\end{array}$ & $\begin{array}{l}2 \cdot 31 \\
\text { s.d. } 0 \cdot 31\end{array}$ \\
\hline $\begin{array}{l}\text { Mean time from onset to final } \\
\text { macular threshold (months) } \\
\text { Proportion with red/green colour } \\
\text { defect in affected eye at follow-up }\end{array}$ & $\begin{array}{l}16 \cdot 6 \\
35 \% \\
\text { s.e. } 7 \cdot 28\end{array}$ & $\begin{array}{l}21 \cdot 3 \\
46 \% \\
\text { s.e. } 7 \cdot 98\end{array}$ & $\begin{array}{l}35 \\
59 \% \\
\text { s.e. } 9 \cdot 13\end{array}$ \\
\hline
\end{tabular}

TABLE 3. Factors producing transient amaurosis

\begin{tabular}{lc}
\hline \multicolumn{1}{c}{ Factor } & No. of patients \\
\hline Affective disturbance & 20 \\
Exercise & 15 \\
Temperature change & 10 \\
Menstruation & 10 \\
Unknown & 4 \\
Increased illumination & 4 \\
Eating & 2 \\
Smoking & 1 \\
\hline
\end{tabular}

presenting visual acuity of $6 / 36$ or better was considerably less than that for non-smokers, the difference, $20.4 \%$, fell just short of twice the standard error $(20.8 \%)$. At follow-up, no significant differences were found between smokers and non-smokers in the mean field indices, nor in the proportion reaching a visual acuity of 6/6. The mean macular threshold of the low smoking group (Group B) was significantly lower than the mean threshold for non-smokers $(P<$ $0.05)$ although there was no significant difference between heavy smokers and non-smokers. The proportion of heavy smokers developing a red/green colour defect in the affected eye was significantly higher than for non-smokers $(P=0 \cdot 05)$.

\section{Discussion}

Although tobacco is clearly implicated in the pathogenesis of tobacco amblyopia and in the optic neuropathy of pernicious anaemia (Freeman and Heaton, 1961), its possible effect on the visual prognosis in patients with optic neuritis due to multiple sclerosis had not been previously studied. In a study of cyanide metabolism and $\mathbf{B}_{12}$ levels in smokers with multiple sclerosis (Matthews, Wilson and Zilkha, 1965), there were no significant differences between patients and smoking controls, and hydroxycobalamin has been shown to be of no value in the treatment of multiple sclerosis (Simpson, Newell and Miller, 1965).

The high incidence in this series of transient blurring after an attack of optic neuritis is surprising but in only one case was smoking the provoking factor.

Although there were differences in macular thresholds found between non-smokers and light smokers, a similar difference was not found between nonsmokers and heavy smokers. This discrepancy cannot be explained by variation in length of follow-up as the shortest follow-up was for the non-smoking group. Recurrent subclinical attacks of optic neuritis might have influenced the final macular thresholds recorded but, in that case, the group with the longest mean follow-up (Group C) should have been the most affected. For these reasons the results of the present investigation are inconclusive. Variation in body temperature, which is known to affect visual function in optic neuritis (Namerow, 1968), might 
have influenced the final results since it was not controlled in this study.

There is a significantly higher incidence of red/ green colour defects in the affected eye in heavy smokers compared with non-smokers. Possibly heavy smoking per se puts the optic nerve at a disadvantage metabolically so that any additional insult produces a greater degree of impairment. A further study on this aspect would appear necessary, with more frequent sampling of the various indices of visual function during the follow-up period.

The way in which smoking can exacerbate some of the symptoms and signs of multiple sclerosis is uncertain. Although nicotine can reproduce them (Spillane, 1955) it is conceivable that other constituents of cigarette smoke may also be involved. Whether nicotine has a direct effect on nerve function within the central nervous system is equally uncertain. Considerable problems arise in relating animal experiments, often with high concentrations of nicotine, to the human situation. There is good evidence that nicotine can stimulate cholinergic sites at the Renshaw inter-neurone (Ginzel, 1967), thus explaining its depressant action on the monosynaptic knee jerk (Van Harreveld and Feigen, 1948) and the observation that smoking could dramatically lessen spasticity in familial spastic paraplegia (Webster, 1964); the reverse, i.e. the exacerbation of spasticity by smoking, has however also been recorded (Spillane, 1955). Experiments on the action of nicotine on synaptic transmission in the spinal cord have usually shown no effect (Van Harreveld and Feigen, 1948), although synaptic blocking has been described with high concentrations (Takagi and Comura, 1958). Blocking in the peripheral nervous system occurs only with high concentrations, but this may not be at the synaptic level (Vazquez and Toman, 1967). There is some evidence that, in normal individuals, smoking increases the frequency of the fast phase of vestibular-induced nystagmus (Tibling, 1969) and critical flicker frequency (Larson, Finnegan and Jaag, 1950; Barlow and Baer, 1967), presumably by increasing the speed of conduction in CNS pathways. A depression in amplitude of flash responses immediately after smoking a cigarette has been observed (Vazquez and Toman, 1967) but little work has been published on the effect of smoking on the visual evoked responses in healthy subjects.

Factors causing Uhthoff's syndrome include exercise, hot bath and food, possibly because of the associated muscular, cutaneous or splanchnic vasodilatation. Experiments on total cerebral blood flow suggest that it is unaffected or even increased by smoking or nicotine (Kuhn, 1967; Miyazaki, 1970; Ingenito, Barrett and Procita 1971; Hall, 1970) though these results for total flow may mask differing regional effects.
If visual blurring in patients with multiple sclerosis is not due to the vascular effects of smoking, then it may be due to a direct effect of nicotine which could act either by depressing retinal ganglion cell function, blocking transmission in demyelinated nerve fibres, blocking synaptic transmission at the lateral geniculate body, or depressing receptor cells in the striate cortex. Parsons (1901) suggested that nicotine could paralyse synaptic transmission in cone fibres and depression of frog retinal action potentials has been demonstrated with nicotine in high concentration (Therman, 1938). In the cat, nicotine has a mildly stimulant effect on lateral geniculate neurones (Curtis and Davis, 1963); it can also abolish visual evoked responses recorded from the optic lobes of frogs but this effect again depends on a high concentration applied locally (Libet and Gerard, 1938).

In view of the increasing evidence that the Uhthoff phenomenon is related to increased body temperature and is due to conduction block in partially demyelinated nerve fibres (Davis and Jacobson, 1971) it is tempting to postulate that nicotine may have a similar effect. Such an hypothesis could be tested experimentally by demonstrating whether nicotine, in low concentration, affects conduction in partially demyelinated nerve fibres; clinically, the measurement of visual evoked responses (Halliday, McDonald and Mushin, 1973) during smoking or intravenous nicotine could confirm increasing block by alterations in latencies.

\section{References}

BARLOW, D.H. \& BAER, D.J. (1967) Effect of cigarette smoking on the critical flicker frequency of heavy and light smokers. Perceptual and Motor Skills, 24, 151.

Courville, C.B., Maschmeyer, J.E. \& Delay, C.P. (1964) Effect of smoking on the acute exacerbations of multiple sclerosis. Bulletin of the Los Angeles Neurological Society, 29, 1.

Curtis, D.R. \& Davis, R. (1963) The excitation of lateral geniculate neurones by quaternary ammonium derivatives. Journal of Physiology, 165, 62.

DAvis, F.A. \& JACOBSON, S. (1971) Altered thermal sensitivity in injured and demyelinated nerve. Journal of Neurology, Neurosurgery and Psychiatry, 34, 551.

Freeman, A.G. \& Heaton, J.M. (1961) The aetiology of retrobulbar neuritis in Addisonian pernicious anaemia. Lancet, i, 908.

GINZEL, K.H. (1967) Introduction to the effects of nicotine on the central nervous system. Annals of the New York Academy of Sciences, 142, 101.

Graham, J.G. \& OpPenheimer, D.R. (1969) Orthostatic hypotension and nicotine sensitivity in a case of multiple system atrophy. Journal of Neurology, Neurosurgery and Psychiatry, 32, 28.

HALL, G.H. (1970) Effects of nicotine and tobacco smoke on the electrical activity of the cerebral cortex and olfactory bulb. British Journal of Pharmacology, 38, 271.

Halliday, A.M., McDonald, W.I. \& Mushin, J. (1973) Visual evoked response in diagnosis of multiple sclerosis. British Medical Journal, iv, 661. 
Ingenito, A.J., Barrett, J.P. \& Procita, L. (1971) An analysis of the effects of nicotine on the cerebral circulation of an isolated perfused, in situ cat brain preparation. Stroke, $2,67$.

Johnson, R.H., DE J. Lee, G., OpPenheimer, D.R. \& SPALDING, J.M.K. (1966) Autonomic failure with orthostatic hypotension due to intermediolateral column degeneration. A report of two cases with autopsies. Quarterly Journal of Medicine, 35, 276.

KuHN, R.A. (1967) Mode of action of tobacco smoke inhalation upon the cerebral circulation. Annals of the New York Academy of Sciences, 142, 67.

LARSON, P.S., FinNegan, J.K. \& JAAG, H.B. (1950) Observations on the effect of cigarette smoking on the fusion frequency of flicker. Journal of Clinical Investigation, 29, 483.

LiBET, B. \& GeraRD, R.W. (1938) Automaticity of central neurones after nicotine block of synapses. Proceedings of the Society for Experimental Biology, 38, 886.

Matthews, D.M., Wilson, J. \& ZilkhA, K.J. (1965) Cyanide metabolism and vitamin $\mathbf{B}_{12}$ in multiple sclerosis. Journal of Neurology, Neurosurgery and Psychiatry, 28, 426.

MiYAZAKI, M. (1970) Circulatory effects of cigarette smoking, with special reference to the effect on cerebral haemodynamics. Japanese Circulation Journal, 33, 907.

NAMEROW, N.S. (1968) Circadian temperature rhythm and vision in multiple sclerosis. Neurology (Minneapolis), 18, 417.

PARSONS, J.H. (1901) Action of nicotine upon nerve cells. Journal of Physiology, London, 26, 38.
Rose, F.C. (1972) In: The Optic Nerve (Ed. by J. S. Cant), p. 217. Henry Kimpton, London.

Rose, F.C., FriedmanN, A.l., Bowden, P.M.A. \& Perkin, G.D. (1972) In: Multiple Sclerosis, a Reappraisal (Ed. by D. McAlpine, C. E. Lumsden and E. D. Acheson), 2nd edn, p. 151. Churchill Livingstone, Edinburgh and London.

Simpson, C.A., Newell, D.J. \& MilleR, H. (1965) The treatment of multiple sclerosis with massive doses of hydroxycobalamin. Neurology (Minneapolis), 15, 599.

SPILlane, J.D. (1955) The effect of nicotine on spinocerebellar ataxia. British Medical Journal, ii, 1345.

TAKAGI, S.F. \& CoMURA, Y. (1958) Effect of nicotine on the synapse of the central nervous system. American Journal of Physiology, 192, 447.

Therman, P.O. (1938) The neurophysiology of the retina in the light of chemical methods of modifying its excitability. Acta Societatis scientiarum fennicae, Series B, 2, 49.

Tibrling, L. (1969) The influence of tobacco smoking, nicotine, $\mathrm{CO}$ and $\mathrm{CO}_{2}$ on vestibular nystagmus. Acta otolaryngologica, 68, 118.

VAzQuez, A.J. \& Toman, J.E.P. (1967) Some interactions of nicotine with other drugs upon central nervous function. Annals of the New York Academy of Sciences, 142, 201.

van Harreveld, A. \& Feigen, G.A. (1948) Effect of nicotine on spinal synaptic conduction and on polarisation of spinal cord. Journal of Neurophysiology, 11, 141.

WEBSTER, D.D. (1964) The dynamic quantitation of spasticity with automated integrals of passive motion resistance. Clinical Pharmacology and Therapeutics, 5, 900. 